https://helda.helsinki.fi

Shortcut to success? : Negotiating genetic uniqueness in global biomedicine

\title{
Tarkkala, Heta
}

2018-10

Tarkkala , H \& Tupasela , A 2018 , ' Shortcut to success? Negotiating genetic uniqueness in global biomedicine ' , Social Studies of Science , vol. 48 , no. 5 , pp. 740-761 . https://doi.org/10.1177/03063127188

http://hdl.handle.net/10138/307594

https://doi.org/10.1177/0306312718801165

unspecified

acceptedVersion

Downloaded from Helda, University of Helsinki institutional repository.

This is an electronic reprint of the original article.

This reprint may differ from the original in pagination and typographic detail.

Please cite the original version. 
FINAL DRAFT, ACCEPTED FOR PUBLICATION IN SOCIAL STUDIES OF SCIENCE (Vol 48, Issue 5, 2018)

\title{
Shortcut to success? Negotiating genetic uniqueness in global biomedicine
}

\section{Heta Tarkkala}

Department of Social Sciences, University of Eastern Finland, Finland

Faculty of Social Sciences, University of Helsinki, Finland

\section{Aaro Tupasela}

Section of Health Services Research, Department of Public Health, University of Copenhagen, Denmark

\begin{abstract}
Since the sequencing of the human genome, as well as the completion of the first Human Genome Diversity Project, the benefits of studying one human population over another has been an ongoing debate relating to the replicability of findings in other populations. The leveraging of specific populations into research markets has made headlines in cases such as deCode in Iceland, Quebec Founder Population, and Generation Scotland. In such cases, researchers and policy makers have used the genetic and historical uniqueness of their populations to attract scientific, commercial and political interest. In this article, we explore how in countries with population isolates, such as Finland, the researchers balance considerations relating to the generalization and replicability of findings in small yet unique research populations to global biomedical research interests. This highlights challenges related to forms of competition associated with genetics research markets, as well as what counts as the 'right' population for genetic research.
\end{abstract}

\section{Keywords}

genetic homogeneity, population genetics, pharmacogenomics, stratified medicine, population branding

\section{Correspondence:}

Heta Tarkkala, Department of Social Sciences, P.O. Box 111, 80101 Joensuu, Finland Email: heta.tarkkala@helsinki.fi

\section{Introduction}

After the initial sequencing of the first human genome (International Human Genome Sequencing Consortium, 2001) and the development of high-throughput sequencing, it became increasingly possible and inexpensive to capture the genetic variation that was present among human populations around the world (Gannett, 2001). Initiatives included such sequencing projects as the 1000 Genomes project (Birney and Soranzo, 2015), the 100000 genomes project in the UK and the 
All of Us Research Program in the US. ${ }^{1}$ New analytical approaches, such as Genome Wide Association Studies (GWAS), were important in identifying variants associated with disease and other traits, generating a narrative of quickly identifying disease-causing variations. One of the challenges, which emerged out of these new technical and methodological possibilities, was identifying those populations that researchers considered representative enough to make replicable generalizations across human populations, while at the same time being competitive in terms of price and speed of delivery. In this article, we explore how researchers and biobank experts in small countries, such as Finland, seek to balance considerations relating to the generalization and replicability of findings in small, yet unique, research populations to global biomedical research interests. These efforts seek to generate both scientific interest, as well as economic investment. This discussion contributes to studies, which focus on the processes through which human tissue samples and related health information are made productive within global biomedical research markets (cf. Parry, 2004; Sunder Rajan, 2006; Waldby and Mitchell, 2006).

The Nordic countries have been consistently described by policy makers and medical researchers as a 'gold mine' for genetic research (Nordforsk, 2014; Palotie et al., 2000), due to their high-quality biobanks, extensive population registers and lenient informed consent practices (Soini, 2013). Frank (2000) has even suggested that the Nordic countries are cohorts in which the whole nation serves as the study population. Perhaps the best-known example of this has been deCode, with its interest in studying the Icelandic population (Fortun 2008; Pálsson 2007; Rose, 2001, 2003), but a number of other small population examples exist, such as the Faroe and Orkney Islands (Jorgensen et al., 2004; Zara, 2015). In this context, most Nordic countries have sought to market and brand their populations as being unique and useful for biomedical research (Tupasela, 2017; Tupasela and Tamminen, 2015). Countries such as Finland (Tupasela et al., 2015) and Iceland (Rose, 2003) draw on narratives of homogeneity to position themselves as competitors in the global biomedical research market. Initiatives in other countries, such as Mexico (Kent et al., 2015: 846), India (Sunder Rajan, 2006: 165), Brazil (Gibbon, 2013), Singapore (Ong, 2016) and Estonia (Fletcher, 2004), have drawn on historico-cultural narratives of national genetic heterogeneity to brand themselves as ideal targeted populations for medical research.

It is important to note, however, that these efforts have drawn on a strong policy narrative of market imaginaries of biobanks and populations as a new type of market resource. Experience has shown, however, that the marketization of populations is not as straightforward as originally thought. DeCode, for example, despite being referenced as an example of the marketization of the Icelandic population, has gone through multiple bankruptcies and been repeatedly re-sold to new owners (see also Aarden, 2017 on the Singapore Tissue Network). Similarly, the biobanking community has become increasingly concerned and interested in the long-term sustainability of their activities given the difficulties they have had in attracting investment and recouping expenses from services (Aarden, 2017; Vaught et al., 2011). Biobank bankruptcies and solvency problems have become an important concern for biobankers in general (Tupasela and Stephens, 2013). These challenges, however, have not stifled national attempts to make biobanks and populations attractive for international research collaboration, as well as investment.

In addition to the aforementioned national contexts, geneticists have sought to draw on unique population isolates to study diseases. Researchers have suggested that population isolates such as the Amish, Hutterites, Mennonite and Pima Indians (Varilo and Peltonen, 2004) are unique populations, which can be used to study disease-causing genes using smaller sample sizes because of their perceived homogeneity. Population isolates have been argued to confer specific advantages 
in studying disease because the populations are seen to live in more uniform environments, have better genealogical and clinical records, have reduced genetic variability, and can have an enrichment of some phenotypes and diseases (Zara, 2015: 110). These arguments, however, invariably raise questions about what constitutes homogeneity, isolate populations and uniqueness, which would confer some type of research advantage over other populations. As Krieger (2012: 634) has noted, 'who and what makes a population has everything to do with whether population means are meaningful or meaningless, with profound implications for work on population health and health inequalities'. The valorization of both heterogeneous and homogenous populations as ideal types for medical research is an important phenomenon in that both rely on reified notions of population and population history.

Discussions within pharmacogenetics and genetics have introduced new forms of debates about the 'right' type of population for medical research (cf. Epstein, 2007). In their study of pharmacogenomics in Brazil, for example, Ventura Santos et al. (2015: 48) have argued that there is an ongoing valorization of race mixture or genomic heterogeneity as a resource for translational genetic research by Brazilian geneticists. Fujimura and Rajagopalan (2011) have argued that in their attempts to avoid categories of race in their analyses, many researchers produce simultaneously different kinds of populations, as well as population differences. Likewise, Shim et al. (2014: 581) show that researchers 'produce homogeneity along some dimensions and heterogeneity along others in their study populations', and thus that these concepts are situational, not inherent in their study populations. Furthermore, in thinking about the emergent field of niche marketing within pharmacogenomics (Epstein, 2007) it has become apparent that policy makers (as opposed just geneticists) may seek to position national or regional populations so as to attract a broader research interest in their populations (Tupasela, 2017). Indeed, many countries develop research markets based on their populations and the concomitant data (Hoeyer, 2016). Simultaneously contemporary biomedical research is increasingly becoming data-intensive, requiring large samples in order to gain statistical significance. By using vast sample and data collections, researchers hope to produce meaningful results about complex multi-variant diseases with methods such as GWAS (see i.e. Visscher et al., 2012). What countries such as Finland seek to market, however, is the ability to gain statistical significance of finding disease-causing genes, by being able to use fewer samples than other population collections use.

In this article, we explore how geneticists in Finland negotiate the genetic uniqueness of the Finnish population in order to attract international research funding and partners, while at the same time being able to make claims of easier and quicker paths to identifying disease causing genes. This requires convincing collaborators of the usability and replicability of findings in small populations for further studies in larger populations. At the same time, these very same populations should 'fit in' into large collaborative research projects that require data serving high-level research goals.

We are interested in this connecting of potentials to populations for several reasons. First, the term 'unique' population appears to refer to complementary virtues in genetics; arguments for the benefits and drawbacks of both homo- and heterogeneous populations appear to draw on the similar set of arguments to generate meaningful results. Second, there is an ongoing debate among the biomedical research community as to which types of populations are best suited for studying disease causality and pharmacogenetic outcomes (Montoya, 2011; Weiss and Terwilliger, 2000); different actors argue in favor of heterogeneous or homogeneous populations. In countries such as Finland and Iceland, small populations with less variation are seen as a shortcut to success and a competitive advantage over heterogeneous populations where identifying genetic markers may require larger and more expensive sample sizes (Zara, 2015). Third, the discussions surrounding 
genetic uniqueness and homogeneity are closely related to questions of inclusion and identity, by which we mean that population characterizations rely heavily on developing selection criteria (Lipphardt, 2010; Prainsack, 2007: 85). For instance, in Taiwan the claim of the unique population requires balancing between the four main ethnic groups - groups that Tsai (2010) shows to be more hybrid and open to contestation than the practices of a population biobank in Taiwan would suggest. In Singapore, the uniqueness and claimed potential usefulness of the collection in Biopolis comes from the claim that it represents all of 'Asia' (Ong, 2016). Finally, as populations become an interest for national marketing and innovation policy, their potentiality in scientific use becomes increasingly framed according to the demands of market forces, as well as driven by what nations consider their market niches. This may run counter to the interests of the research community and generate tensions among competing scientific programs, which in turn produces a need for further negotiations between scientists (both commercial and academic) and policy makers as to the purposes of national collections.

\section{Material and methods}

Our general interest in studying unique populations, such as population isolates, stems from two interrelated research trajectories. The trajectory undertaken by Tarkkala has had its roots in a PhD research project on sample quality discussions and debates within the global biobank community, and their alignment for sample use with clinics, industry and university research. The second trajectory, which Tupasela has been pursuing in his research, relates to the marketization of population samples and its relations to the construction of national narratives of identity and sovereignty (cf. Tupasela, 2016). In combining these two perspectives, we began by examining international cases in which notions of homogeneity and heterogeneity have been deployed as arguments for what constitutes 'good' samples and collections for biomedical research. In this article, we focus on one particular substantiation of this debate using Finland as a case, but relating it to other similar cases found globally.

Our broader data set consists of official documents, newspaper articles, and scientific articles from a number of international cases - Mexico (Benjamin, 2009), Brazil (Gibbon, 2016; 2013), Quebec (Hinterberger, 2012), Iceland (Pálsson, 2007), Singapore (Ong, 2016), Taiwan (Tsai, 2010), and Finland (Tupasela et al., 2015) - where these debates have taken place and which have received social scientific or anthropological research attention. We have sought to use these cases to identify the key dynamics in the debate between the benefits of one type of population over another (homoand heterogeneity), as well as the ways in which these categories are constructed. In addition to documents and articles, we draw on the specific case of Finland, where we have collected and analyzed official documents, public scientific presentations, newspaper articles, radio interviews, field notes and scientific articles.

We have conducted almost 50 semi-structured interviews with informants in Finland between 2011 and 2016. The informants we interviewed worked in establishing biobanks, mainly in Finland, in different ways: they were researchers, clinicians or worked for the biobanks. Some key informants were interviewed two or even three times and in some interviews multiple informants were present. The field notes were based on public presentations held on the topic, as well as site visits. We collected these materials as they came by and whenever there was an opportunity to participate in such events and conferences. ${ }^{2}$ 
In order to understand the significance that discussions surrounding homogeneity and heterogeneity in the Finnish population, it is necessary to recognize the history of medical research in Finland and its relationship to historico-cultural notions of Finnishness (Tupasela, 2015). Appiah (2005: 151) has noted that 'upholding differences among groups may entail imposing uniformity among them'. Such processes of imposing uniformity among groups may create new categories whose relevance in international research markets may not be clear. The construction of difference in a medical sense began in Finland in the 1960s, with a number of studies examining what has been termed the Finnish population 'structure'. HR Nevanlinna (1922-1994), who was one of Finland's foremost medical experts in population genetics, notes in an early study into Finnish population structure, where ethnic groups were understood and studied in relation to whether they spoke Finnish or Swedish: 'In order to avoid contamination among these and some smaller ethnic groups as well, the sampling was made from the rural population only' (Nevanlinna, 1972: 195). The search for polymorphic and rare marker genes in the Finnish population was, therefore, from the outset based on identifying and studying families and population isolates ('super isolates'). Over several generations, these super isolates gave rise to the enrichment of particular disease genes and polymorphisms, which were used to 'illustrate the peculiar structure of the Finnish rural population' (Nevanlinna, 1972: 196). Similar studies conducted during the same time, such as on congenital nephrosis (Norio, 1966), also provided important insights into the ways in which heredity and inbreeding in small communities - which researchers later described as a homogenous population contribute to such peculiarities. Already at this early stage, there was an interest to make delineations as to which groups of people could be included and excluded from the study samples.

These genetic peculiarities, however, also came at a price. Since many of the genetic variations were unique to the Finnish population, the ability to extrapolate and generalize about them to other populations was also a challenge. Although the notion of homogeneity made it easier to find gene variants in smaller sample populations, it also raised the issue of whether this was something unique to Finland. Finnish researchers were concerned about whether this was of any interest to the international research community or nothing more than a local curiosity, which did not have actionable medical significance for others. With the recent increased internationalization of biomedical research and the increased policy pressure to make national collections visible and matter globally, there has been an interest in highlighting the usability of these collections (Ministry of Social Affairs and Health, 2015; see also Ministry of Health, 2017 for a Danish example). We see these negotiations as providing important insights into the increased intertwining of market demands and scientific considerations in global biomedical research.

Intertwined scientific and commercial markets are central to our account. Scientific markets concern the academic prestige and visibility provided by international scientific publications, as well as by claims to discovery and knowledge of unique diseases (Tupasela, 2016). Commercial markets center on the ability to attract private partners, in the form of pharmaceutical and diagnostic companies to partner with and invest money in Finnish research groups. The two cannot be neatly separated, but rather re-enforce the authority of the other, as can be seen in the case of deCode.

In the following, we first discuss how research markets are emerging within global biobanking. Then we discuss this phenomenon in the case of Finland, relating it to the fluidity of categories of homogeneity and heterogeneity. Finally, we will discuss the further connections of these categories to the scientific production of knowledge more generally.

\section{Constructing markets for genetics research}


In this paper we explore a particular type of genetic research market, representing a small fraction of the types of markets that exist for human tissue. Markets for sperm, egg, blood, specific cells, cell lines and whole organs represent a much larger physical and financial portion of the transactions that take place on a day to day basis (Andrews and Nelkin, 2001; Lewis, 2004). Our focus is on general and disease-specific collections related to the expected outcomes of the Human Genome Project. Unlike, for example, the US, the genetics research in the Nordic countries has mainly been driven and led by the public sector and there is considerable political interest in the translation of these resources into financial, medical and academic returns, to justify public expenditures (cf. Tripp and Grueber, 2011). Finland has traditionally been understood as a Nordic welfare state, where healthcare and research have been seen to belong to the public sector. During the past 20 years, however, Finnish politics - like that of many other countries - has sought to seek new avenues through which public services and resources can be made more productive (Allardt, 1998; Häyrinen-Alestalo and Peltola, 2006). The market-orientation of biobanking activities in Finland can be attributed to the rise of innovation policy thinking in Finland at the turn of the millennium, which also led to changes in the roles that public universities were seen to have (Häyrinen-Alestalo and Peltola, 2006).

A recent example of the market-oriented approach adopted within Finnish policy-making has been the Finnish Genome Strategy (Ministry of Social Affairs and Health, 2015), followed by a roadmap for Health Sector Research and Innovation (Ministry of Employment and Economy, 2016).

According to the Genome Strategy there is a need 'to ensure that Finland becomes an attractive country for top level international research and innovation utilizing genomic data' (Ministry of Social Affairs and Health, 2015: 15). Among the key advantages of Finland, it is stated in the strategy, is that 'Finns are genetically relatively homogenous' which plays a key role in identifying 'genetic mechanisms targeted by drugs ... in a manner that is difficult, if not impossible, elsewhere' (Ministry of Social Affairs and Health, 2015: 13).

Another example of how the Finnish innovation environment is framed and marketed as a potential source of interest comes from SITRA, an independent innovation fund, which has developed a series of PowerPoint slides widely used by the stakeholders (policy makers and researchers alike) to market Finland. In the slide series, SITRA (2015) highlights Finland's possibilities as a 'testbed for [the] next generation of research and medical innovation'. In these slides, the genetically isolated population is named as a competitive factor and a cost-efficiency for investors in Finnish research. Moreover, as Tarkkala et al (2018) argue, the growing role of the Ministry of Employment and Economy in the development of the Finnish health sector shows how scientific endeavors are increasingly connected to expectations of economic interest. This type of interest and industry collaboration is exemplified in a recent announcement of FinnGen (2018) - a research project that aims to analyze biobank samples from 500000 Finnish donors in order to utilize the 'unique gene pool to find the next breakthroughs in disease prevention, diagnosis and treatment' and to 'create a co-operation model between public sector and healthcare industry' eventually benefitting 'citizens, businesses, biobanks and research - and ultimately the entire world'.

The scientific study of the population and attracting outside investment and interest have tended to go hand-in-hand. This line of thinking and imaginary has been best exemplified by the writings of two of Finland's best-known geneticists and proponents of Finnish genetic homogeneity: 
The information produced from the analysis of the material would most likely have a great impact on the national economy. The achieved results could create the opportunity to utilize funds invested into the Finnish healthcare system to commercializing the new knowledge and even offer the possibility to partially finance the healthcare system of tomorrow.

(Palotie and Peltonen-Palotie, 2004: 1712, authors' translation)

The idea that collecting samples from the population would reap benefits to partially finance the Finnish welfare state in the future is indicative of how market thinking has penetrated scientific discourses of Finnish genetics. Large-scale Finnish biobanks founded in the 2010's operate mainly in connection with publicly funded clinical hospitals, with the aim of benefitting future patients through today's public-private partnerships, such as collaborations with international pharmaceutical companies (Tarkkala et al., 2018).

\section{DNA $^{\text {TM }}$ at the edge of the inhabitable world}

Benjamin (2009: 353) has argued that nation states and their efforts to brand DNA should be 'understood as a strategic calibration' of population classifications 'as socio-political or biological entities - whose value is constantly mediated in the context of specific scientific, political, and economic institutions'. Examples of this 'strategic' calibration can be seen, for example, in the Genetic Map of Europe (Lao et al., 2008), where countries, such as Finland, have sought to show their genetic uniqueness through visual technologies of difference. The generation of these differences, however, requires a process in which researchers select specific individuals or subpopulations to serve as genetic representatives (Tupasela and Tamminen, 2015; Tupasela, 2016).

Among Finnish scientists, the discussion surrounding uniqueness can be found in the leveraging of founder populations and population isolates as exemplars of unique populations, which can be used to identify disease-causing variants effectively. Peltonen et al. (1999: 1913) state, for example:

'Finland, located at the edge of the inhabitable world, is one of the best-studied genetic isolates. The characteristic features of population isolates - founder effect, genetic drift and isolation - have, over the centuries, shaped the gene pool of the Finns.' This perspective of the uniqueness, together with the benefits it could offer to study disease has been reinforced within contemporary Finnish discourse on the usefulness of Finns in biomedical research. It seeks to position Finns as a unique isolate, while at the same time being able to speak to the broader global questions being studied among geneticists.

But where did the discourse of a homogenic and unique Finnish population come from? The effects of population isolates and founder effects on rare genetic diseases gave rise to what is known as Finnish Disease Heritage (FDH), which is a group of 36 rare Mendelian, mostly recessive, disorders that are over-represented in the Finnish population (Nevanlinna, 1972; Norio, 2000; Norio et al., 1973). The Finnish population has an increased frequency of rare and uncommon variants that are almost absent in other European populations (Kurki et al., 2014: 2). The early work done on monogenetic rare diseases in Finland between 1960s and early 1990s was related to the forming of population history and the narrative of genetic uniqueness. The history of migration related to founder populations was also assumed to reflect the isolation of the rest of the population when it came time to study more complex diseases. The so-called Finnish homogeneity, however, has required that specific forms of exclusion and inclusion be practiced in the sampling conducted in 
these studies. The exclusion of people whose grandparents came from different villages, the exclusion of specific minorities, such as the Samì and Roma, ${ }^{3}$ and the exclusion of more recent arrivals from Somalia and Russia, have helped to generate, in part, a genetically homogenous image of the population. On the other hand, individuals who married within the same village, as well as those descended from population isolates became representatives of Finnishness at the genetic level.

As in Mexico (Anaya-Munoz et al., 2017), the Finnish population has been studied using different sampling strategies and statistical methods. Studies on Mexican populations have drawn on two approaches; the first strategy 'unpacks fine-grained genetic variation - favoring precision and realism', while 'the latter tends to flatten individual differences and historical depth in lieu of generalization'. Indeed, the first approach 'incorporates multiple disciplinary resources into sampling design and interpretation', while the second 'privileges pragmatic considerations over more robust multidisciplinary analysis' (Anaya-Munoz et al., 2017: 89). Similarly, in Finland, the work on FDH and monogenetic diseases simultaneously produced a population history that highlighted uniqueness and isolation (Tupasela, 2016). Others, however, have highlighted the differences and subpopulations of the country. For example, Lahermo et al. (1996) show the differences between the Finnish Saami population and 'the Finns', while Lappalainen et al. (2006: 207) studied Y-chromosomal markers and showed that 'the western and eastern parts of the country have been subject to partly different population histories, which is also supported by earlier archaeological, historical and genetic data'. They go on to argue that it is important to incorporate 'Y-chromosomal data to reveal the population substructure that is often left undetected in mitochondrial DNA variation'. From this methodology they conclude that the 'early assumptions of the homogeneity of the isolated Finnish population have now proven to be false, which may also have implications for future association studies' (Lappalainen et al., 2006: 207). As a matter of fact, Lappalainen et al. (2006: 214) suggest in their paper that even the homogeneity of the maternal mitochondrial DNA among Finns might prove to be false once the regional differences in mitochondrial DNA are thoroughly studied. ${ }^{4}$ Another paper by overlapping authors 'warn[s] against a priori assumptions of homogeneity among Finns or other seemingly isolated populations' (Salmela et al., 2008: e3519).

Such criticisms, however, have not lessened claims of Finnish homogeneity. A number of other examples can be found in scientific texts discussing homogenous and heterogeneous populations as the best approach to study disease-causing variants. Varilo and Peltonen (2004: 316) have argued about the benefits of studying population isolates using new sequencing technologies: 'These new prospects have highlighted once again the question of the best study samples for the complex genemapping efforts, isolates versus more heterogeneous populations and families vs case-control samples.' This line of argumentation can be found in numerous later articles. Lim et al. (2014: 2), for example, note that their study 'articulates substantial advantages for studying the rare variation in complex phenotypes in founder populations like the Finns and by combining a unique population genetic history with data from large population cohorts and centralized access to national health registers' (emphasis added). Kurki et al. (2014: 1) argue that their study 'illustrates the utility of population isolates, familial enrichment, dense genotype imputation and alternate phenotyping in search for variants associated with complex diseases'. Similarly, others have argued that population isolates, such as those found in Finland, offer 'an exciting opportunity to identify rare and lowfrequency variants associated with complex diseases' (Chheda et al., 2017: 477). Indeed, Wang et al. (2014) argue in their study that the 'power of rare-variant association tests is higher in the Finnish population'. 
This line of argumentation can be seen as a way of strategically aligning sample collections (and thus populations) with efforts to leverage scientific expertise and research resources into international research markets. In the following, we highlight the challenges and difficulties that researchers have in balancing the arguments of uniqueness with those of validity and generalizability in other populations. This is the key tension: The population must remain generalizable enough to attract international partners, while remaining unique enough to confer a competitive advantage in terms of finding disease-causing genes with small sample sizes.

\section{The difficulties of defining populations}

Defining population boundaries among human groups poses several challenges for geneticists. In our interviews it was apparent that despite the strong national narrative of uniqueness, geneticists were very aware of the difficulty of defining population boundaries and their meaningfulness from a biological, let alone a clinical perspective. In one interview that we conducted, a geneticist explained:

The biological definition of a population does not work very well with humans. It is spoken of as a type of nation-state-ethnic group, ethnic group is perhaps much closer to it. Our use of the term is also not always consistent, so if I started to think about Finnish populations then I would perhaps group Finnish-Swedes as some type of sub-population, as well as East and West Finns separately. But then we also use 'Finnish population' as an umbrella term under which there is all types of diversity. So in human genetics I don't think there is a consistent definition which would have criteria, so it is used differently depending on the situation. (interview with geneticist, 2011)

The concern over consistency regarding the definition of a population is a challenge for genetics in general, since geneticists may draw on differing criteria of exclusion and inclusion for particular study populations (cf. Montoya, 2011: 47). In Finland, this has also been the case since researchers 'construct' (Tupasela et al., 2015) populations to meet their research needs (see Montoya, 2011: 162 for a discussion on 'population labelling'). This process invariably leads to reified notions of which genetic characteristics become aligned with certain groups of people, as well as those living within a particular nation-state. Indeed, the process gives rise to the definition of what those very groups are. The notion of diversity in this sense can take on multiple meanings and ends up being a relative term through which geneticists can position their study populations in relation to others. As another geneticist noted in an interview:

I would not use the term 'homogeneous'. I would say that in Finland there is little genetic diversity. Because I know that Sally used the term homogeneity to mean little diversity. They are not the same thing because homogeneity means that it is the same all over and that is not entirely true in Finland. (interview with geneticist, 2012)

The way that this geneticist uses the terms, it is possible to have a population which has less genetic diversity, but at the same time cannot be considered to be homogeneous. This can be explained, for example, that a given population may have little genetic diversity, but the diversity that it does have reflect clear genetic differences among those found. The researcher pointed out in the interview that both Finns and Icelanders could be considered homogeneous, but that Finns have less genetic diversity, which, according to them, makes for a better population to identify disease-causing variants. The use of the term 'homogeneity' to mean both being same all over and having little 
diversity has significance for leveraging research populations in international research markets. Homogeneity is a problem for extrapolating and relating one research population to others, while little diversity means that there is less genetic 'noise' for which the researchers need to account to find significance. In interviews, Finnish geneticists used 'genetic homogeneity' and 'uniqueness', although the latter could also allow for heterogeneity and be drawing attention to another characteristic among populations.

A challenge that arises from discussions about genetic uniqueness and how it is constructed derives from the reference populations that researchers use:

[I]n part, the uniqueness ('omintakeisuus') is the result of not using reference populations from the East in our studies. (interview with molecular geneticist, 2016)

Reference populations play a significant role in the construction of similarity and difference among individuals and populations and thus play an important role in notions of Finnish homogeneity. They serve as baselines against which other genetic samples are compared. The decisions associated with inclusion and exclusion in reference populations, as well as about which reference populations are used, can lead to the over- or under-emphasis of similarity and difference among populations. Following Hey's (2015) discussion on the 'robustness' of concordant evidence, the selection of reference populations allows for similarity and difference to be generated methodologically. Salmela et al. (2008), for example, have noted that in their analysis 'the Finnish-Swedes stood out from the rest of Western Finland only when Sweden was included in the analysis, which highlights the importance of relevant reference populations also when detecting patterns of variation within a country'.

Different reference populations will generate different types of similarities and differences (for a discussion on fixing standards of reference see also M'charek, 2005: 86). Choosing one reference population over another will help to align similarity and difference among different lines of preference. For Finnish research, this has more often than not led to an alignment along 'European' genetic ancestry, as opposed to Russian and Baltic ancestry. This can be explained in part by the exclusion of reference populations from Russian and Baltic areas. In many ways, this has led to the construction of the idea that Finns are an outlier in Europe which sounds odd, given the interest that Finnish researchers have had in aligning themselves with European ancestry. As one geneticist noted:

I think that regardless of reference population Finns are genuinely some type of outliers. Not so much as it appears in these publications, because there are bridges from the Baltics and I'm sure we will find other outliers. For example, the Samì have not had their whole genome studied, but I am sure they are much further away. (interview with a geneticist, 2015)

As a concept, the notion of outlier is a somewhat ambiguous. It suggests isolation and purity, despite the rough consensus that there are no 'pure' populations (see Gibbons, 2017). Yet the interview excerpt above is significant in that it shows how being stable or 'genuine' must always be connected with or 'bridged' to somewhere else in order to find a rootedness or 'tethering' (Hinterberger and Porter, 2015). The relationship between being an outlier and having bridges to other populations is at the core of the difficulty in generating genetic uniqueness while maintaining similarity and significance for other research populations. 
In the following section, we will move our attention to looking at the ways in which 'outliers' or population isolates are positioned and used to attract research collaborations.

\section{Isolates as a shortcut to success}

The challenge with heterogeneous populations, according to some, is that in order to identify significant mutations or other 'signals' one needs a large number of samples with good clinical data on the patients. This is both expensive and difficult to achieve. Countries like Finland and Iceland claim a competitive advantage because of their populations with relatively little genetic diversity, as well as good clinical records. A person working in a biobank described the benefits of a small and homogenous population in the following way:

In this kind of population, which is homogeneous with big enough $\mathrm{N}$, the relative signal noise is much more beneficial. So even the smaller, rarer genetic changes, which are then causing a certain phenotype, we can observe them in Finnish population a) with considerably smaller group of those needing to be studied, which means number of genotyped people, than in many other or almost all other populations. And even that $b$ ) we do get a signal at all. That you can see the signal from the noise in the first place. And then it is statistics to count how these relations go and if you hunt for rare enough variations, then you do not see them in some typical European populations but you have to come to Iceland or Finland .... (interview with a biobank expert, 2016)

What many researchers see as a shortcut to success and was aptly described in one of our interviews by a geneticist, who highlighted the role of long linkage disequilibrium (LD) ${ }^{5}$ in providing efficacy when used in a meaningful way in a specific population. LD refers to 'the nonrandom association of alleles at two or more loci' (Slatkin, 2008: 477). This is said to help not only in understanding 'past evolutionary and demographic events' but also 'to map genes that are associated with quantitative characters and inherited diseases, and to understand the joint evolution of linked sets of genes'.

The linkage disequilibrium ... is often not beneficial when it is long. It reduces the variation and then it is harder to find the causative gene. But you can fight against this with these rare variants that have concentrated in Finland. And if we can find these broken genes from the locus ... if we can show that these people have for instance this disease, then it is sort of a shortcut to success. (interview with a geneticist, 2016)

Researchers also described linkage disequilibrium in relation to the competitive advantage that unique populations have in relation to heterogeneous populations, when used right. As one researcher framed the issue in concrete terms:

We had 68 patients and 136 controls for the genome wide SNP analysis, which helped identify the gene. If you took an American or British study population, where the background of people may be from all over the world, then the genetic variability is so great that you could not do this with the small sample sizes that we use here. And that is the advantage that we have had that you can do the analysis, which have been expensive with a smaller number of samples. (Interview with a geneticist, 2012) 
To highlight the advantages of one population requires the ability to draw distinctions between other possible competitors. As we have mentioned, there are examples from around the world in which homogeneity is claimed to be a strength for attracting research interest. Iceland has one such population, which some researchers consider to be relatively homogeneous and for which there are excellent clinical records. Finns argue for a significant advantage of the Finnish population over that of Iceland: size. In addition to being homogeneous (in the sense of having low diversity) and having good clinical records, the Finnish population of 5.5 million is much larger than that of Iceland's, which is slightly over 320 000. From a statistical perspective, researchers in Finland claim this to be a competitive advantage, in that they are able to draw on a much larger homogeneous population. In one of our interviews, a biobank expert described this benefit:

Yes, the homogeneity, the level of similarity in genome connected to a relatively big population, big N, it is a combination you do not have in the same way in other places. There are smaller populations, which are on my opinion still, like Kuusamo [a small town in the North of Finland known to have a small founder population] is then a truly exceptional case, but like ... hundreds of thousands, let's say like Icelanders, to some extent they might be more homogeneous as a group but there are only some hundreds of thousands of them. We have some millions who are - perhaps not as homogeneous - but almost as homogeneous. (Interview with a biobank expert, 2016)

Homogeneity and isolation emerge as negotiated and relative categories when speaking to geneticists and experts. In our interviews, Finnish geneticists always discussed notions of homogeneity (or variation) and isolates in relation to others. For example, Kuusamo, a region in Northern Finland, which geneticists consider an isolate based on a founder population of 34 families and low level of migration, is differentiated from the Finnish population, which was also discussed as a type of macro-isolate (i.e. Zara, 2015: 110). Finnish geneticists see both as types of isolates or outliers, but they are isolates and outliers in relation to a specific research task and interest. The Kuusamo population cannot perform the same utility and function that a national isolate can. Similarly, Iceland, which geneticists also consider a homogeneous population and a type of macro-isolate, was seen to have some benefits, but not others (such as a large N). Therefore, different populations begin to take on a type of specific research function, which is then 'marketed' to international research markets for specific research purposes. Additionally, researchers using the Finnish population isolate as a marketing strategy want to meet the requirements of being able to provide a 'big N'. The number of samples and data to which researchers have access is crucial to negotiating uniqueness; a homogeneous population is not too small, not too homogeneous, and not too odd.

\section{Confirming usability of population isolates: Replicability and its consequences for uniqueness}

In a public lecture on biobanking, the head of Helsinki Biobank, Kimmo Pitkänen, described Finland as an excellent environment in which to advance personalized medicine. He identified the Finnish population and its genetic heritage as a strength, but he presented this strength in terms of a balance between being different and yet not too different: He presented Finns as 'European' but 'different than other Europeans' (also Palotie, 2017). According to Pitkänen:

Finns are an interesting population in terms of our genetic characteristics, that is our genome, in that sense that we are among ourselves reasonably similar and a bit different than other Europeans or nations, even in the world, which means that here in the Finnish 
environment we can identify those genetic differences that are behind certain diseases ... much better than in other populations. We sort of have a lot less noise here. (Pitkänen, 2016)

In most international scientific genetic research articles, for editors to accept the publication the research group has had to find another population in which it can replicate its result (cf. Ioannidis et al., 2001). In studies using population isolates, there is a risk of finding a genetic risk factor that is unique to the population. How do you sell an important risk factor to the international scientific community when it cannot be shown to have the same effect anywhere else? This is the dilemma for many researchers and biobanks working with unique populations, and which researchers raised as a problem in our interviews. ${ }^{6}$ As one Finnish researcher noted in an interview:

Actually, we think that for marketing purposes you should not highlight that we are complete freaks. We should say that we have these certain strengths that make this and that possible, but it needs to be validated in some other population then as well. Because it turns a bit in the direction that if you find a marker in this odd population, then ... who cares? Like big pharma, globally ... But instead it is just the route to the verification in a larger population. (interview with a biobank expert, 2016)

The perspective of balancing between uniqueness and general usability elsewhere was confirmed in a number of informal discussions that Tarkkala had during her fieldwork. As one biobank manager noted in discussions related to their collections:

We have to say to our potential customers and collaborators that we are not that unique! (fieldnotes, discussion with a biobank expert, 2015)

The success stories of usability do not work for everyone. Many researchers globally are not interested in the so-called Finnish 'uniqueness' in terms of genes or genomes. Some collaborators or potential customers might think that Finnish samples are not useful for them because they are too odd or too homogeneous. If researchers studying large prospective cohorts want to find collaborators and partners and show that their collections are usable, they have to be able to convince others that their samples produce replicable results, and so in some cases the biobank operators have to start by contesting the uniqueness of their collections in terms of genetic heritage. Consequently, they emphasize other benefits instead, such as good clinical records that also help in stratifying the populations for the given research setting (Tarkkala et al., 2018).

The relationship between unique populations and replication also raises another challenge for the discourse of unique populations. Once researchers are able to replicate a specific result in another population, what is the uniqueness of the original population? If researchers are able to replicate a particular genetic trait or marker, then the uniqueness aspect of the original populations comes into question. The Finnish population remains unique only as long as it is Finnish. Issues about the replication of findings in other populations also raise questions about which populations are the right ones to use for replication studies and what standards of uniqueness and generalizability are being generated through such processes. 
Another example of this balancing act can be found in an interview on the Finnish public broadcasting channel YLE, which was discussing Finnish biobanks and their strengths. The journalist asks from a biobank expert Anu Jalanko:

Leena Mattila: We [Finns] are a genetically unique population. So what kind of specialties can one find in the gene banks here?

Anu Jalanko: Our materials are often selected to international research projects. We have this Finnish genetic background of ours, it has less variation and it has been considered that it could be easier to find these common diseases related gene variants from our materials because our heterogeneity is not so substantial. We do not have proper examples yet, but we do think that one can find the so called rare variants from our materials when research on diseases is done and in this way we might be able to find people who are healthy despite the fact that they have genetic risks or lifestyle risks and these rare variant persons can then be used as models when for example a medicine is under study. (Mattila, 2015)

In the following example, a prominent Finnish researcher, who also promotes Finnish collections abroad, presents in a public lecture the case of loss-of-function variants, which are relatively frequent in the Finnish population. He confirms the reasoning based on isolation around 'special kinds of genes', and he describes the loss-of-function genes as 'protective'. In the research literature, it has been stated that loss-of-function mutations 'in genes encoding drug targets can provide a unique insight into the potential efficacy and safety of therapeutic modulation using that drug' (Stitziel and Kathiresan, n.d.).

Not all genes are risk genes, some of them are protective, some of them protect from certain diseases and now it happens to be so that based on our isolation the amount of such genes has increased in our population that are very ... that can be searched for from that point of view that they are protective genes. And then they are of great importance for drug development. So the basic idea is that if we have some gene whose function is completely shut down and it protects us from, for instance, heart and coronary/vascular diseases, then it could be a good target for drug development.

(Palotie, 2017)

These kinds of arguments about the usability of population isolates reinforce some lines of research done in Finland. Not only do researchers bring their own research area and its scientific significance to the foreground, but they also help build a market for Finnish biobanks internationally.

\section{Conclusions: Negotiating uniqueness}

We have argued that designating populations as unique or homogeneous has consequences for the 'marketability' and usefulness of collections in international collaboration. So-called homogeneous populations or population isolates may allow for easier identification of possible disease-causing genes, but may be difficult to replicate in other populations. In the Finnish case, the construction of homogeneity through selective sampling leads to balancing between potential weaknesses and strengths. Finnish researchers have had problems publishing certain results, because they could not find a population in which their findings could be replicated. Drawing on notions of uniqueness and homogeneity, then, can be counterproductive for some population studies. 
Researchers use the term homogeneity differently to refer to different population characteristics. Some researchers use the term to signify ethnic homogeneity (cf. Pehkonen et al., 2017), while others use it to signify reduced genetic variability. Reduced genetic variability, however, may still allow the population to contain substantially different sub-populations. Both homogeneity and reduced genetic variability, however, are used as arguments that populations can support quick and inexpensive routes to identifying disease-causing genes, which researchers can then verify in heterogeneous populations. Researchers also negotiate uniqueness as a factor of relative small population sizes, noting that Finland is a relatively large population isolate, making it more useful and applicable than are smaller populations. Uniqueness also comes to carry other meanings, including having good and comprehensive clinical records.

Researchers in Finland are constantly trying to show difference, while claiming enough similarity to fit in with international research collaborations and consortiums: the branding of a population as unique should not make it too odd so as not to be replicable. For our informants, it was of great importance that their sample collections fit in with large, international data sets and cohorts. The consequences of this are that Finnish researchers sometimes downplay the uniqueness argument when similarity is a prerequisite for fitting in. Researchers working with other unique populations and population isolates, and seeking international collaboration, similar same challenges.

The emphasis on sampling Finnish sub-populations that have been sedentary over the centuries, and the exclusion of ethnic minorities (particularly the Samì and Roma populations), point towards a valuation process in which migration and mobility are considered exclusionary criteria for genomic studies. The need to negotiate uniqueness in international collaborations, however, raises questions about the usefulness of this strategy. The strategy also contributes to the stratification of the population with respect to the possibilities and hopes attached to possible findings: Are those findings only going to be meaningful for those whose genetic lineages have been sampled and studied?

The construction (Tupasela, 2016) of unique populations can lead to distortions in the sociohistorical framing of populations, leading to different types of inclusion and exclusions, such as in Taiwan (Tsai, 2010: 452). Our study of Finnish researchers and biobankers shows the alignment work necessary to allow for unique populations to fit into large international collaborations. As Shim et al. (2014: 581) argue, 'we see the fluidity of race and ethnicity and their potential malleability into other notions of population similarities and differences that may be as or more meaningful for disease etiology'. Our study has shown that population studies pose unique challenges in terms of replication. Findings from population studies using more heterogeneous populations may not be applicable or useful for so-called unique populations, while studies which rely on so-called unique populations may have difficulty in replicating in larger, more heterogeneous populations. We see this conundrum as giving rise to different forms of population politics within genetics research.

\section{Acknowledgments}

We would like to thank Sara Green, Mervi Kuronen, Mette Nordahl- Svendsen and the Personalized Medicine in the Welfare State research group, three anonymous reviewers and Sergio Sismondo. 


\section{Funding}

Academy of Finland Grant numbers 132554 and 292408, COST-Action IS1303 Citizen's Health Through Public-private Initiatives: Public Health, Market and Ethical Perspectives (CHIP ME),

\section{References}

Aarden E (2017) Projecting and Producing 'Usefulness' of Biomedical Research Infrastructures; or Why the Singapore Tissue network Closed. Science and Public Policy 44(6): 753-762.

Allardt E (1998) Teknologiaretoriikka suomalaisen todellisuuden konstruoimisen välineenä. Tiede \& Edistys 2. [Technology rhetoric as a tool for constructing Finnish reality]

Anaya-Muñoz VH, García-Deister V and Suárez-Díaz E (2017) Flattening and Unpacking Human Genetic Variation in Mexico, Postwar to Present. Science in Context 30(1): 89-112.

Andrews L and Nelkin D (2001) Body Bazaar. The Market for Human Tissue in the Biotechnology Age. New York: Crown Publishers.

Appiah KA (2005) The Ethics of Identity. Princeton: Princeton University Press.

Benjamin R (2009) A Lab of Their Own: Genomic sovereignty as postcolonial science policy. Policy and Society 28(4): 341-355.

Birney W and Soranzo N (2015) The end of the start for population sequencing. Nature 526: 52-53.

Chheda H, Palta P, Pirinen M, et al. (2017) Whole-genome View of the Consequences of a Population Bottleneck Using 2926 Genome Sequences from Finland and United Kingdom. European Journal of Human Genetics 25(4): 477-484.

Epstein S (2007) Inclusion - The Politics Of Difference In Medical Research. Chicago: University of Chicago Press.

FinnGen (2018) FinnGen research project is an expedition to the frontier of genomics and medicine. Available at: www.finngen.fi/en (accessed 10 Jan. 2018).

Fletcher A (2004) Field of Genes: the Politics of Science and Identity in the Estonian Genome Project. New Genetics and Society 23(1): 3-14.

Fortun, M (2008) Promising Genomics - Iceland and deCODE Genetics in a World of Speculation. Berkeley, CA: University of California Press.

Frank L (2000) When an Entire Country Is a Cohort. Science 287(5462): 2398-2399. 
Fujimura JH and Rajagopalan R (2011) Different Differences: The use of 'genetic ancestry' versus race in biomedical human genetic research. Social Studies of Science 41(1): 5-30.

Gannett L (2001) Racism and Human Genome Diversity Research: The Ethical Limits of 'Population Thinking'. Philosophy of Science 68(3): S479-S492.

Gibbon S (2013) Ancestry, Temporality, and Potentiality. Current anthropology 54(Suppl 7): S107-S117.

Gibbon S (2016) Translating Population Difference: The Use and Re-Use of Genetic Ancestry in Brazilian Cancer Genetics. Medical Anthropology 35(1): 58-72.

Gibbons A (2017) There's no Such Thing as a 'Pure' European - or Anyone Else. Science. DOI: $10.1126 /$ science.aal1186.

Hey SP (2015) Robust and Discordant Evidence: Methodological Lessons from Clinical Research. Philosophy of Science 82: 55-75.

Hinterberger A (2012) Investing in Life, Investing in Difference: Nations, Populations and Genomes. Theory, Culture \& Society 29(3): 72-93.

Hinterberger A and Porter N (2015) Genomic and Viral Sovereignty: Tethering the Materials of Global Biomedicine. Public Culture 27 (2): 361-86.

Hoeyer K (2016) Denmark at a Crossroad? Intensified Data Sourcing in a Research Radical Country. In: BD Mittelstadt \& L Floridi (eds), The Ethics of Biomedical Big Data. Switzerland: Springer Publishing Company, pp. 73-93.

Hästbacka J, de la Chapelle A, Kaitila I, et al. (1992) Linkage disequilibrium mapping in isolated founder populations: diastrophic dysplasia in Finland. Nature Genetics 2(3): 204-211.

Häyrinen-Alestalo M and Peltola U (2006) The Problem of a Market-oriented University. Higher Education 52: 251-281.

International Human Genome Sequencing Consortium (2001) Human Genome. Nature 409: 860921.

Ioannidis JPA, Ntzani EA, Trikalinos TA and Contopoulos-Ioannidis DG (2001) Replication validity of genetic association studies. Nature Genetics 29: 306 - 309.

doi:10.1038/ng749

Jorgensen, TH, Buttenschön HN, Wang AG, Als TD, Børglum AD and Ewald H (2004) The origin of the isolated population of the Faroe Islands investigated using Y chromosomal markers. Human genetics, 115(1): 19-28.

Kent M, García-Deister V, López-Beltrán C, Santos RV, Schwartz-Marín E and Wade P (2015) Building the genomic nation:'Homo Brasilis' and the 'Genoma Mexicano' in comparative cultural perspective. Social Studies of Science 45(6): 839-861. 
Krieger N (2012) Who and What is a 'Population? Historical Debates, Current Controversies, and Implications for Understanding 'Population Health' and Rectifying Health Inequalities. The Milbank Quarterly 90(4): 634-681.

Kurki MI, Gaál EI, Kettunen J, et al. (2014). High risk population isolate reveals low frequency variants predisposing to intracranial aneurysms. PLoS Genetics 10(1): e1004134.

Lahermo P, Sajantila A, Sistonen P, et al. (1996) The genetic relationship between the Finns and the Finnish Saami (Lapps): analysis of nuclear DNA and mtDNA. American Journal of Human Genetics 58(6): 1309-1322.

Lao O, Lu TT, Nothnagel M, Junge O, Freitag-WolfS., Caliebe M, Balascakova M, Bertranpetit J, Bindoff L, Comas D et al. (2008) Correlation Between Genetic and Geographic Structure in Europe. Current Biology 18: 1241-1248.

Lappalainen T, Koivumäki S, Salmela E et al. (2006) Regional differences among the Finns: A Ychromosomal perspective. Gene 376(2): 207-215.

Lewis G (2004) Tissue Collection and the Pharmaceutical Industry: Investigating Corporate Biobanks. In: Corrigan, O. \& Tutton, R. (eds.) Genetic Databases - Socio-Ethical Issues in the Collection and Use of DNA. Routledge, London. pp. 181-202.

Lim ET, Würtz P, Havulinna A et al. (2014) Distribution and Medical Impact of Loss-of-function Variants in the Finnish Founder Population. PLoS Genet 10(7): e1004494.

Lipphardt V (2010) The Jewish community of Rome: An isolated population? Sampling procedures and bio-historical narratives in genetic analysis in the 1950s. BioSocieties 5(3): 306-329.

Mattila L (2015) Tiedeykkönen: Mitä tapahtuu biopankeissa ja konservatiivin ja liberaalin aivoissa? Yle 1. 28.4.2015. Available at: http://areena.yle.fi/1-2690326 (accessed 5.11.2015). [What happens in biobanks and in the brains of the conservative and the liberal?]

M'Charek A (2005) The Human Genome Diversity Project: an ethnography of scientific practice. Cambridge: Cambridge University Press.

Ministry of Employment and Economy (2016) Innovating together: Growth Strategy for Health Sector Research and Innovation Activities: The Roadmap for 2016-2018. MEE guidelines and other publications 8/2016. Available at: http://urn.fi/URN:ISBN:978-952-327-142-5 (accessed 15.12.2017)

Ministry of Health (2017) National strategy for personalized medicine 2017-2020. Available at: http://www.sum.dk/ /media/Filer\%20-\%20Publikationer_i_pdf/2017/Personalised-MedicineSummary/SUM_klar_diagnose_summary_UK_web.ashx (accessed 27.2.2017)

Ministry of Social Affairs and Health (2015) Improving Health through the Use of Genomic Data. Finland's Genome Strategy. Working Group Proposal. Ministry of Social Affairs and Health 
Raportteja ja muistioita 34/2015:34. Available at: http://www.julkari.fi/handle/10024/126940 (accessed 24.01.2017)

Montoya MJ (2011) Making the Mexican Diabetic. Race, Science, and the Genetics of Inequality. Berkeley: University of California Press.

Nevanlinna HR (1972) The Finnish Population Structure - A Genetic and genealogical Study. Hereditas 71: 195-236.

Nordforsk (2014) Joint Nordic Registers and Biobanks - A Goldmine for health and Welfare Research. Nordforsk policy Paper 5. Oslo: Norden.

Norio R (2000) Suomi-Neidon Geenit. Tautiperinnon Takana Juurillemme Johtamassa. Helsinki: Otava. [The Finnish Maidens Genes. Finding the roots of our disease heritage]

Norio R (1966) The Nephrotic Syndrome and Heredity. Human Heredity 19: 113-120.

Norio R, Nevanlinna HR and Perheentupa J (1973) Hereditary Diseases in Finland; Rare Flora in Rare Soil. Annals of Clinical Research 5(3): 109-141.

Ong A (2016) Fungible Life: Experiment in the Asian City of Life. Durham \& London: Duke University Press.

Palotie A (2017) 'Suomalaisten hankalat geenit' Studia Generalia - Olen suomalainen, 16.2.2017, Helsingin yliopisto. Available at:

https://www.helsinki.fi/fi/unitube/video/94b37c41-b26f-4f09-b838-7f53522e2bd8, (accessed 10.4.2017) [The tricky genes of the Finns. Studia Generalia: 'I am Finnish' -public lecture]

Palotie A and Peltonen-Palotie L (2004) Pitäisikö perustaa suomalainen biopankki?

Epidemiologisten aineistojen hyödyntäminen on kaikkien etu. Duodecim 120: 1710-12. [Should a

Finnish biobank be founded. Utilizing our epidemiological data is in everyone's interest]

Palotie L, Palotie A and Lange K (2000) Use of population isolates for mapping complex traits. Nature Reviews Genetics 1: 182-190.

Pálsson G (2007) Anthropology and the New Genetics. Cambridge: Cambridge University Press.

Parry B (2004) Trading the genome - Investigating the Commodification of Bio-Information. Columbia University Press: New York.

Pehkonen J, Viinikainen J, Böckerman P, Lehtimäki T, Pitkänen N and Raitakari O (2017) The Challenge of GxE Research: A Rejoinder. Social Science \& Medicine 188: 204-205.

Peltonen L, Jalanko A and Varilo T (1999) Molecular Genetics of the Finnish Disease Heritage. Human Molecular Genetics 8: 1913-23. 
Pitkänen K (2016) Mikä on biopankki? A public presentation at: Ole osana tiedettä Biopankkitoiminta HUS:ssa -event 29.9.2016, Biomedicum, Helsinki. [What is a biobank? A public presentation at the 'Be part of science - biobanking at the HUS' -event]

Prainsack B (2007). Research Populations: Biobanks in Israel. New genetics and society 26(1): 85103.

Rose H (2001) The Commodification of Bioinformation: The Icelandic Health Sector Database. London: The Wellcome Trust.

Rose H (2003) The Commodification of Virtual Reality: The Icelandic Health Sector Database. In: Goodman AH, Heath D, and Lindee MS (eds), Genetic Nature/Culture: Anthropology and Science beyond the Two-Culture Divide, Berkeley: University of California Press, pp. 77-94.

Salmela E, Lappalainen T, Fransson I et al. (2008) Genome-wide analysis of single nucleotide polymorphisms uncovers population structure in Northern Europe. PloS one 3(10): e3519.

Shim JK, Darling KW, Lappe MD, et al. (2014) Homogeneity and heterogeneity as situational properties: Producing - and moving beyond? - race in post-genomic science. Social Studies of Science 44(4): 579-599.

Sitra (2015) SitraFinland-Your test bed for next generation research and medical innovation [PowerPoint presentation] Retrieved from https://www.sitra.fi/uutiset/varasta-tama-uusi-esitys-viesuomen-genomiosaamisen-maailmalle/ (Accessed 10 November 2017)

Slatkin M (2008) Linkage disequilibrium - understanding the evolutionary past and mapping the medical future. Nature Reviews Genetics 9(6): 477-485.

Soini S (2013) Finland On A Road Towards A Modern Legal Biobanking Infrastructure. European Journal of Health Law 20(3): 289-94.

Stitziel NO and Kathiresan S (n.d.) Leveraging human genetics to guide drug target discovery.

Trends in Cardiovascular Medicine. Available from: http:/www.sciencedirect.com/science/article/ pii/S1050173816301281 (accessed 19 May 2017).

Sunder Rajan K (2006) Biocapital. The Constitution of Postgenomic Life. Durham: Duke University Press.

Tarkkala H, Helén I, and Snell, K (2018) From health to wealth: The future of Personalized Medicine in the Making. Futures. https://doi.org/10.1016/j.futures.2018.06.004

Thompson EE, Sun Y, Nicolae D, et al. (2010) Shades of gray: A comparison of linkage disequilibrium between Hutterites and Europeans. Genetic epidemiology 34(2): 133-139.

Tripp S, and Grueber M (2011) Economic Impact of the Human Genome Project.

Battelle Memorial Institute. 
Tupasela A (2017) Populations as Brands in Medical Research - Placing genes on the Global genetic Atlas. BioSocieties 12(1): 47-65.

Tupasela A (2016) Genetic Romanticism - Constructing the Corpus in Finnish Folklore and Rare Diseases. Configurations 24(2): 121-143.

Tupasela A, and Stephens, N (2013) The Boom and Bust Cycle of Biobanking - Thinking Through the Life Cycle of Biobanks. Croatian Medical Journal 54(5): 501-503.

Tupasela A, and Tamminen S (2015) Authentic, Original and Valuable - Stabilizing the Genetic Identity in non-human and Human Populations in Finland. Studies in Ethnicity and Nationalism 15(3): 411-431.

Tupasela A, Snell K, and Cañada J (2015) Constructing Populations in Biobanking. Life Sciences, Society and Policy 11(5).

Tsai Y (2010) Geneticizing Ethnicity: A study on the 'Taiwan Bio-Bank'. East Asian Science, Technology and Society: an International Journal 4(3): 433-455.

Varilo T and Peltonen L (2004) Isolates and their Potential use in Complex Gene Mapping Efforts. Current Opinion in Genetics \& Development 14(3): 316-323.

Vaught J, Rogers J, Carolin T and Compton C (2011) Biobankonomics: Developing a Sustainable Business Model Approach for the Formation of a Human Tissue Biobank. J Natl Cancer Inst Monogr. 42: 24-31.

Ventura Santos R, Oliveira da Silva G, and Gibbon S (2015) Pharmacogenomics, Human Genetic Diversity And The Incorporation And Rejection Of Color/Race In Brazil. BioSocieties 10(1): 48-69.

Visscher PM, Brown MA, McCarthy MI, et al. (2012) Five Years of GWAS Discovery. The American Journal of Human Genetics 90(1): 7-24.

Waldby C and Mitchell R (2006) Tissue Economies - Blood, Organs, and Cell Lines in late Capitalism. Durham \& London: Duke University Press.

Wang SR, Agarwala V, Flannick J, et al. (2014) Simulation of Finnish Population History, Guided by Empirical Genetic Data, to Assess Power of Rare-Variant Tests in Finland. The American Journal of Human Genetics 94(5): 710-720.

Weiss K and Terwilliger J (2000) How Many Diseases Does it Take to Map a Gene with SNPs? Nature Genetics 26: 151-157. doi:10.1038/79866.

Zara I (2015): Population Isolates. In: Zeggini E \& Morris A (eds): Assessing Rare Variation in Complex Traits. Design and Analysis of Genetic Studies. Springer. New York. pp. 107-122. 


\section{Author biographies}

Heta Tarkkala works as a project researcher at the Department of Social Sciences at the University of Eastern Finland. She is also a doctoral student at the University of Helsinki, with a background in sociology. In her research she has been interested in the reorganization of biomedical knowledge production through biobanks, and the development of personalized medicine. She currently works in a project Good(s) for Health - Personalized health services and flexible appropriation of bioinformation.

Aaro Tupasela works as an Associate Professor of ethical, legal, and social aspects of biobanking at the Department of Public Health at the University of Copenhagen. As a sociologist with an interest in Science and Technology Studies, his research has focused on the social aspects of biomedical use of human tissue sample collections and the information that can be gained from them in different contexts. He has also worked on social aspects of rare diseases and population genetics in Finland. Most recently he has been studying international biobanking networks and collaborations in Europe.

\section{Notes}


${ }^{1}$ The 'All of Us Research Program' was previously known as 'The Precision Medicine Initiative'. The program was renamed during the autumn 2016. See: https://allofus.nih.gov/news-events-and-media/announcements/pmi-cohortprogram-announces-new-name-all-us-research-program

${ }^{2}$ We transcribed and coded the interviews thematically with the help of Atlas.ti. We studied different usages of terms, such as population, homogeneity, heterogeneity, uniqueness, variants, competition, market, as well as different contexts where populations came to matter for geneticists and policy makers. These did not necessarily refer specifically to the Finnish population, but to the different ways that the concepts figured in the speech where significance of biobanks for global biomedical research was framed.

${ }^{3}$ It should be noted, however, that the Roma culture have very specific perspectives regarding blood and have not traditionally been trusting towards the medical research community. It is for this reason, erhaps that theiy have not been used in genetic studies, while the Samì have.

${ }^{4}$ A number of other methods have been used to study differences in the Finnish population, including single nucleotide polymorphisms (SNPs), copy number variant (CNV) studies, as well as more contemporary whole genome and whole exome studies. Regardless of the methodology used the construction of homogeneity in many Finnish studies has relied on sampling strategies which exclude significant portions of the population.

${ }^{5}$ Zara (2015: 108) explains how in population isolates with reduced population size due to bottleneck effects and subsequent 'higher levels of inbreeding' the LD amount increases 'consequently modifying the haplotype pattern'. Zara (2015: 108) continues: 'The longer the population recovery takes after the bottleneck, the greater the effect of genetic drift is expected to be. During this process, common variants are rarely lost from an isolate, whereas rare variants may be lost or drift to higher frequencies than in the original population.' In terms of potential for research, again, Finns as a population isolate have been identified as offering advantages for LD studies already 1990's (see i.e. Hästbacka et al., 1992: 209), which is now being reinforced as we show in this article. However, the same long LD that is said to offer advantage may also be a disadvantage. Thompson et al. $(2010,133)$ argue that even though long LD in founder or isolated populations 'is expected to facilitate gene localization, extensive LD may actually limit the ability for gene discovery'.

${ }^{6}$ This is not to say that replication is not important as a basic requirement in biological research. In a wider sense this connects with the problems of 'false positives' and 'false negatives'. However, in this article we discuss the issue in relation to what this methodological requirement might mean when at stake are interests such as conditions that affect only very particular group of people. 